\title{
MONITORING OF CRITICAL WATER AND VEGETATION ANOMALIES OF SUB-SAHARAN WEST-AFRICAN WETLANDS
}

\author{
Linda Moser, Stefan Voigt, Elisabeth Schoepfer \\ German Aerospace Center (DLR), German Remote Sensing Data Center, Muenchner Strasse 20, 82234 \\ Wessling, Oberpfaffenhofen, Germany (email: moser.linda@gmail.com)
}

\begin{abstract}
Surface water is a critical resource in semi-arid westAfrican regions that are frequently exposed to droughts. The application of time series from the Moderate Resolution Imaging Spectrometer (MODIS) to derive spatio-temporal changes of water and vegetation in and around WestAfrican wetlands is demonstrated for the years 2000-2012. A near infrared (NIR) based gradient threshold and calculation of the Normalized Difference Vegetation Index (NDVI) is applied on the time series using the MOD09Q1 surface reflectance product. Surface water dynamics and vegetation anomalies of surrounding regions were found to coincide with the occurrence of drought seasons. This study demonstrates the successful application of remote sensing time series for wetland monitoring.
\end{abstract}

Index Terms - Wetlands, MODIS, time series

\section{INTRODUCTION}

The application of satellite data time series to characterize critical spatio-temporal changes of water and vegetation in wetlands is demonstrated exemplary for selected westAfrican wetland areas in Burkina Faso. In this work, wetlands are defined as areas covered by water during minimum two months per year. Burkina Faso is a semi-arid, land-locked country in the west-African sub-Saharan region. It has been frequently exposed to droughts leading to food crises, particularly in the mid-1970s and 1980s, as well as in the past 15 years. Burkina Faso's freshwater resources are below the international threshold for water scarcity of $1000 \mathrm{~m}^{3}$ inhabitant ${ }^{-1}$ year $^{-1}$ [1].

Wetland mapping and monitoring using time series of medium resolution data has been carried out using different remote sensing sensors and techniques [2], [3]. One of them is a near infrared band (NIR) threshold due to NIR energy being strongly absorbed by water [4], [5]. The Normalized Difference Vegetation Index (NDVI) serves not only to characterize vegetation conditions, but has also been used for studying wetland vegetation, as well as for detection of wetlands in semi-arid areas due to the high contrast to their environment in the dry season [5]. Sensors like the Moderate Resolution Imaging Spectrometer (MODIS) offer additional bands in the blue, green and mid infrared (MIR) range with $500 \mathrm{~m}$ resolution [6], showing a greater potential for further water and vegetation indices [7], [8], however, with substantially decreased spatial resolution. Remotely sensed wetland monitoring in the Sahel region has been carried out for specific study areas [9], [10]. Only few studies have worked consistently on large regions [4], [5], [11] which is challenging due to the high temporal requirements caused by strong seasonal effects, and spatial requirements observing small, but significant wetlands. This study focuses on such a monitoring that can potentially be extended to larger areas.

\section{METHODOLOGY}

The study area is defined as north-south transect ranging from the semi-arid Sahel to the Sudano Savannah in Burkina Faso. The main dataset used in this work are time series from MODIS from 2000 until 2012. The chosen MODIS products are $250 \mathrm{~m}$ surface reflectance (MOD09Q1) for deriving information on surface water and vegetation, and $500 \mathrm{~m}$ surface reflectance (MOD09A1) for the use of quality and state flags. MODIS 8-day red and NIR composites with a resolution of $250 \mathrm{~m}$ were imported. The quality and state flags were resampled to the $250 \mathrm{~m}$ pixel size of the NIR and red bands, and further used for removal of low quality pixels and clouds. Monthly aggregation was carried out for all remaining data on a per pixel level. A slope map was calculated from a digital elevation model (DEM) from the Shuttle Radar Topography Mission (SRTM). Rock outcrops with steep slopes were excluded to avoid misclassifications as water. For surface water detection, a NIR threshold varying along a gradient ranging from $15 \%\left(10^{\circ} \mathrm{N}\right)$ to $25 \%\left(15.5^{\circ} \mathrm{N}\right)$ NIR surface reflectance was chosen based on validation with Landsat data from 2002, 2009, and 2013. 


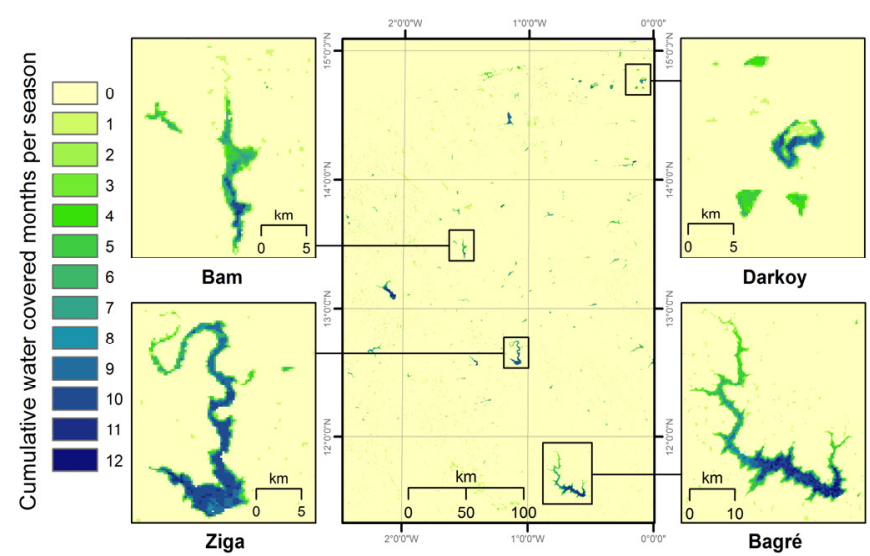

Fig. 1. Cumulative water covered surface area for May 2010-April 2011. Two natural wetlands (Lac Bam, Mare de Darkoy) and two artificial wetlands (Barrage de Ziga, Barrage de Bagré) are shown as examples.

Summing up each of the monthly water masks, a cumulative water covered surface area (Fig. 1) was calculated for each season (May to April of the following year), concluding to a near-permanent water covered area ( $>8$ months/year) or dynamic area (2-8 months/year). The use of the NDVI that was calculated using the red and NIR MODIS bands is twofold: Firstly, anomalies of NDVI dry season sums in the surrounding areas are calculated and compared with spatiotemporal variations of surface water, and the occurrence of droughts (Fig. 2, Fig. 3). Secondly, it aids to detect increasing chlorophyll activities associated with irrigated cultivations around wetlands, or with flooded or floating vegetation in water. Thus, a trend analysis of the anomalies of each year's cumulative water covered surface area, as well as dry season NDVI sums, was carried out (Fig. 4).

\section{RESULTS}

Surface water dynamics are shown as cumulative water covered surface area for the study region. Four examples of different wetlands located along the gradient are highlighted (Fig. 1). The near-permanent area is visualized in shades of blue and the dynamic area in shades of green. A great variability between different wetlands persists. Northern natural wetlands (Lac Bam, Mare de Darkoy and surrounding wetlands) are mostly not water covered throughout the whole year and the dynamic area is larger, whereas large wetlands with dams located further South (Barrage de Ziga, Barrage de Bagré) show relatively large near-permanent areas. In some cases floating vegetation prevents the detection of water, as it is assumed for the example of Darkoy.

The NDVI can be considered as a proxy for vegetation conditions and concludes to intensity or duration of chlorophyll activity during the chosen dry season. Fig. 2 and Fig. 3 show anomalies from the mean of the summed up NDVI values for each respective dry season (Oct-Apr).

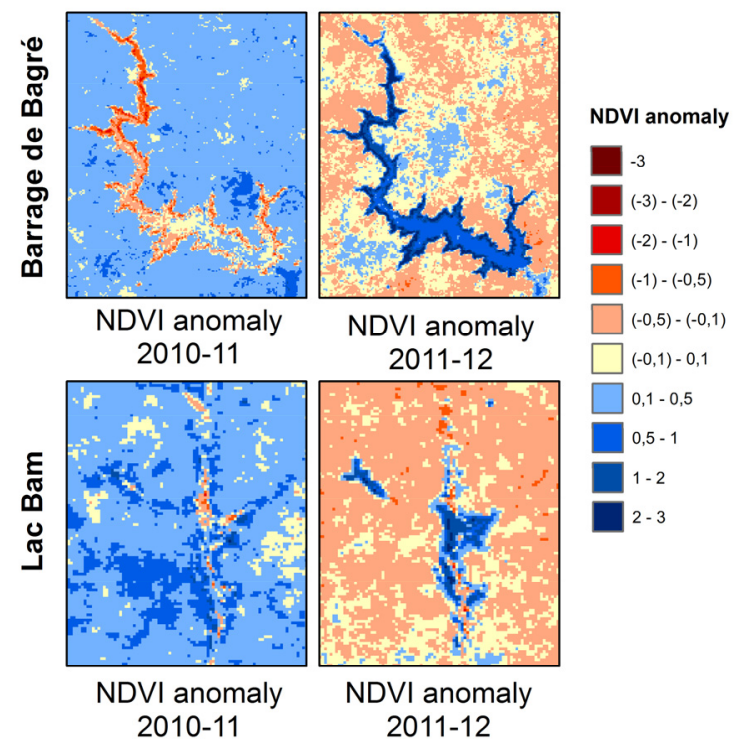

Fig. 2. NDVI anomalies of summed NDVI for the dry seasons (Oct-Apr) for a wet year (2010-11) and a drought year (2011-12), for Lac Bam and Barrage de Bagré.

A wet year (2010-11) and a drought year (2011-12) have been chosen for Barrage de Bagré and Lac Bam, and are displayed in Fig. 2. Orange to red colors indicate negative NDVI anomalies, blue colors positive anomalies. In the 2010-11 wet year the dynamic area inside Barrage de Bagré appears as negative NDVI anomaly with a strongly negative outer boundary, due to longer water coverage. Bam, however, shows a positive anomaly on some of its shoreline that could originate from strong irrigation activities surrounding the wetland during the dry season. In the 2011-12 drought year there is a positive NDVI anomaly in the center of both wetlands that has to be further investigated. The strong positive trend on the coastline of Bagré is assumed to be coastal vegetation due to fast water retreat. Increasing irrigation activities adjacent to the wetlands have been confirmed over the past couple of years based on high resolution Landsat data.

Fig. 3 shows anomalies from the mean of the summed up NDVI values for each dry season (Oct-Apr) between 2000 and 2012, over the whole study area. Wetlands are masked in black. Where drought seasons (2000-01, 200405, 2011-12) are marked in red, NDVI anomalies are mainly negative (red), and have been found to coincide with the smallest area and shortest water coverage of wetlands. In the two seasons of largest water coverage in terms of surface area and duration (2003-04, 2010-11) positive NDVI anomaly trends (blue) of the surrounding area are predominant. 


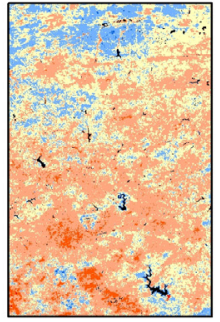

2000-01

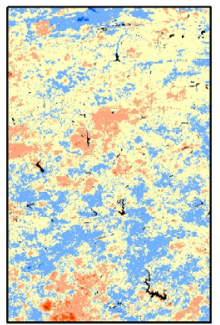

2006-07

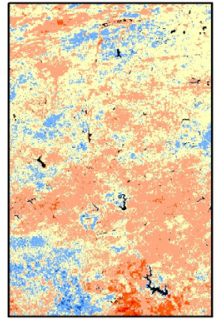

2001-02

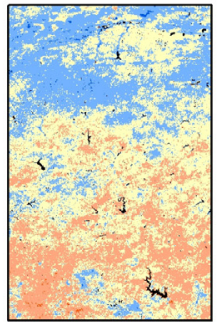

2007-08

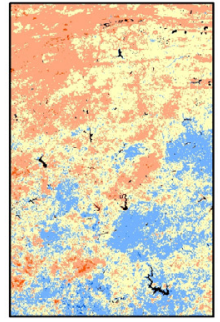

2002-03

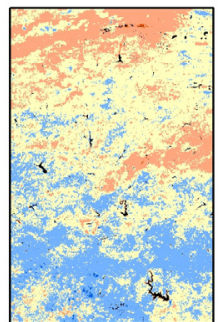

2008-09

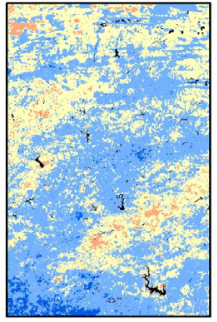

2003-04

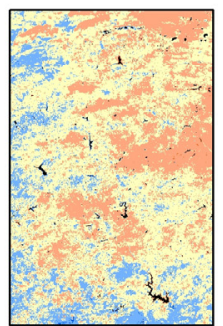

2009-10

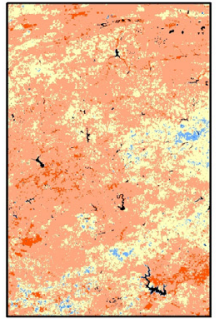

2004-05

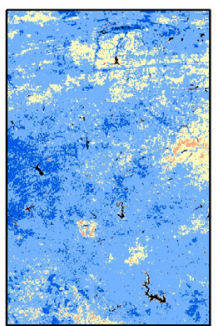

2010-11

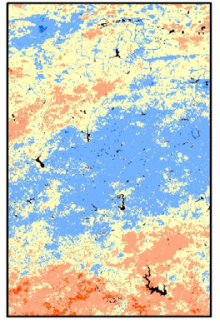

2005-06

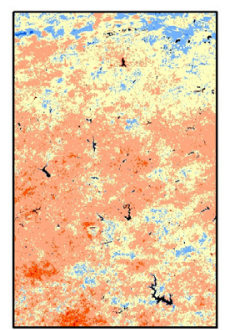

2011-12
NDVI

anomaly

Wetland

(-5) - (-3)

$(-3)-(-2)$

$(-2)-(-1)$

$(-1)-(-0.5)$

$(-0.5)-(-0.1)$

$(-0.1)-0.1$

$0.1-0.5$

$0.5-1$

$1-2$

$2-3$

$3-5$

Fig. 3. NDVI anomalies of summed NDVI for the dry seasons (Oct-Apr) from 2000-01 until 2011-12. Drought years are marked in red.
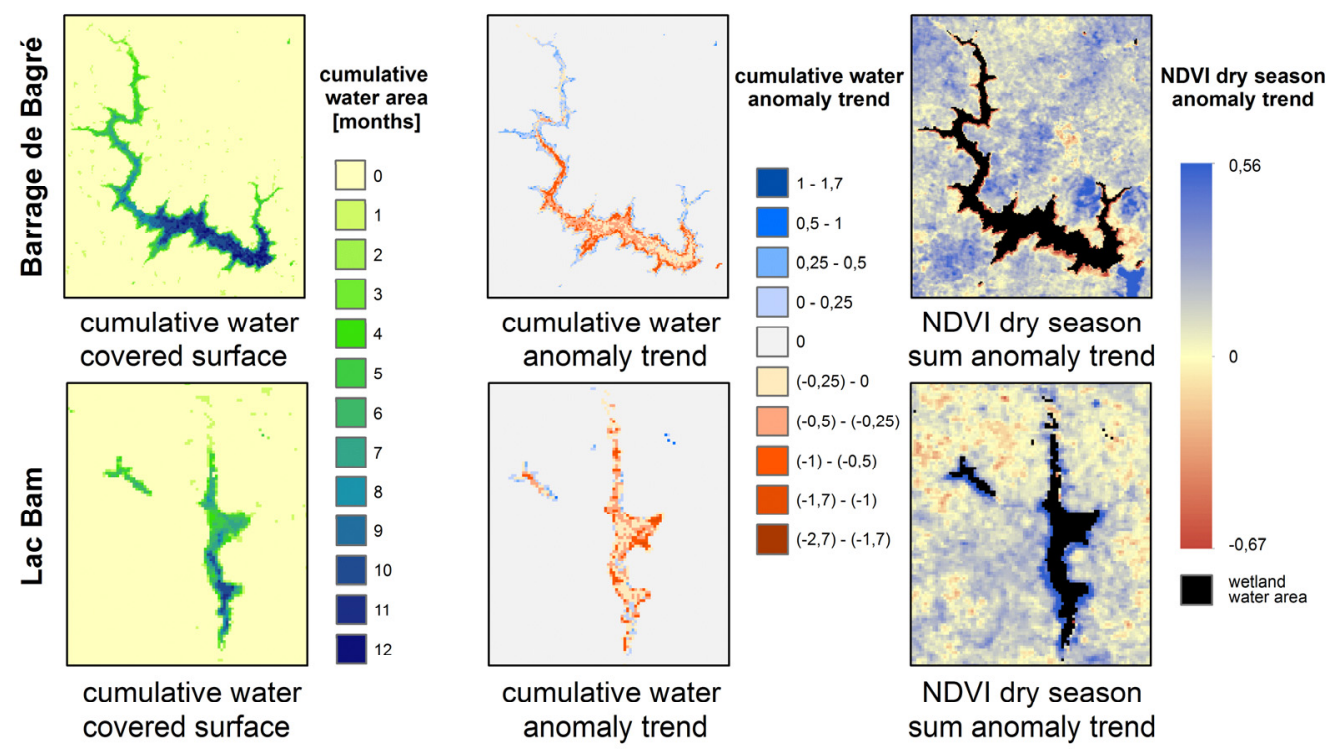

Fig. 4. Cumulative water covered surface area, anomaly trend of the cumulative water covered surface area, and anomaly trend of NDVI dry season sums are shown for Bagré and Bam.

For the two case studies Barrage de Bagré and Lac Bam, Fig. 4 shows the cumulative water covered surface area, the anomaly trend of the cumulative water covered surface area, and the anomaly trend of NDVI dry season sums. Bagré shows a negative anomaly trend of water coverage duration in the center (red), but positive anomalies in the dynamic part (blue), assuming a tendency towards larger water extent, but of shorter duration. Bam shows a general negative trend (red), particularly on its east coast, where standing and floating vegetation in water has been confirmed in recent Landsat imagery. The trend of the dry season NDVI anomalies focuses on the regions close to the coastline, and the water covered area of the two wetlands is masked in black. Lac Bam shows a strong positive trend (blue) adjacent to the coast which concludes to the strong increase of irrigated cultivation. Barrage de Bagré, however, shows the opposite behavior (red), concluding to larger water areas, but no increased cultivation. An exception is the area of large irrigated rice fields in the south-east of Barrage de Bagré. 


\section{CONCLUSIONS}

This work shows the application of MODIS time series for spatio-temporal wetland monitoring. Surface water as well as vegetation can be jointly detected from satellite data and used to describe and categorize important wetland features relevant for better monitoring of critical water shortage situations. Surface water dynamics as well as vegetation anomalies in the surrounding region can be related to the occurrence of drought seasons. Increasing land use activities such as irrigated cultivation around Lac Bam could be detected with MODIS. The vegetation status of a wetland area is more an indicator for the available water during the past months, whereas the water covered area itself can be an indicator on minimum water availability in the coming dry season.

\section{REFERENCES}

[1] M. Falkenmark, "The massive water scarcity threatening Africa - why isn't it being addressed," Ambio, vol. 18, no. 2, pp. 112-118, 1989.

[2] S. L. Ozesmi, and M. E. Bauer, "Satellite remote sensing of wetlands", Wetlands Ecol. Manag., vol. 10, no. 5, pp. 381-402, 2002.

[3] E. Adam, O. Mutanga, and D. Rugege, "Multispectral and hyperspectral remote sensing for identification and mapping of wetland vegetation: A review", Wetlands Ecol. Manag., vol. 18, pp. 281-296, 2010.

[4] I. Klein, A. Dietz, U. Gessner, A. Galayeva, A. Myrzakhmetov, and C. Kuenzer, "Evaluation of seasonal water body extents in Central Asia over the past 27 years derived from mediumresolution remote sensing data", Int. J. Appl. Earth Obs., vol. 26, p. 335-349, 2014.

[5] T. Landmann, M. Schramm, R. Colditz, A. Dietz, and S. Dech, "Wide Area Wetland Mapping in Semi-Arid Africa Using 250Meter MODIS Metrics and Topographic Variables", Remote Sens., vol. 2, no. 7, pp. 1751-1766, 2010.

[6] E. F. Vermote, S. Y. Kotchenova, and J. P. Ray (2011, Feb.), "MODIS Surface Reflectance User's Guide, Version 1.3", Available:

http://modis-sr.ltdri.org/products/MOD09_UserGuide_v1_3.pdf, accessed May 2014.

[7] T. Sakamoto, N. V. Nguyen, A. Kotera, H. Ohno, N. Ishitsuka, and M. Yokozawa, "Detecting temporal changes in the extent of annual flooding within the Cambodia and the Vietnamese Mekong Delta from MODIS time-series imagery", Remote Sens. Environ., vol. 109, pp. 366-374, 2007.

[8] Y. Chen, C. Huang, C. Ticehurst, and L. Merrin, "An Evaluation of MODIS Daily and 8-day Composite Products for Floodplain and Wetland Inundation Mapping," Wetlands, vol. 33, no. 5, pp. 823-835, 2013.
[9] E. M. Haas, E. Bartholomé, E. F. Lambin, and V. Vanacker, "Remotely sensed surface water extent as an indicator of shortterm changes in ecohydrological processes in sub-Saharan Western Africa”, Remote Sens. Environ., vol. 115, pp. 3436-3445, 2011.

[10] J. Gardelle, P. Hiernaux, L. Kergoat, and M. Grippa, "Less rain, more water in ponds: a remote sensing study of the dynamics of surface waters from 1950 to present in pastoral Sahel (Gourma region, Mali)", Hydrol. Earth Syst. Sci. Discuss., vol. 14, pp. 309$324,2010$.

[11] J. F. Pekel, C. Vancutsem, L. Bastin, M. Clerici, E. Vanbogaert, E. Bartholomé, and P. Defourny, "A near real-time water surface detection method based on HSV transformation of MODIS multi-Spectral time series data", Remote Sens. Environ., vol. 140, pp. 704-716, 2014. 